\title{
Internationalization and Civil Engineering Program Innovation
}

\section{Dr. Robert W Fuessle, Bradley University}

Dr. Robert W. Fuessle is a professor serving Bradley University for the past 31 years. He earned his bachelor's degree in mathematics and physics from Monmouth College, and his Masters and PhD degrees in the environmental engineering from the University of Illinois, Urbana. His area of expertise includes hazardous waste treatment by stabilization/ solidification and modeling of environmental systems. He teaches two courses that incorporate international perspectives on sustainability and public policy.

Dr. Al-Khafaji is the Executive Director of the Center for Emerging Technologies in Infrastructure and a Professor of Civil Engineering at Bradley University. He earned his BS in Civil Engineering and MS degree in Construction Management from Wayne State University in Detroit, Michigan. He received a second MSCE in soil dynamics and a Ph.D. in Geotechnical Engineering from Michigan State University in East Lansing, Michigan. Dr. Al-Khafaji is the co-author of 11 engineering textbooks including Numerical Methods, geotechnical, Statics and Dynamics, and software application. These books were used internationally by major institutions. He is also the author of many significant publications in internationally renowned journals. He is responsible for the Innovations Conference in Asphalt and Transportation and the International Construction Innovations Conference. He is the recipient of numerous leadership awards including the 2006 "Man of the Year" Award from the Illinois Asphalt Pavement Association. He is also the only recipient in Bradley's history of all three University excellence awards in Teaching, Scholarship and Public Service. He serves the Easter Seals, W.D. Boyce Council of the Boy Scouts of America, Muscular Dystrophy Association, A Safe Haven Foundation, and the Illinois State Black Chamber of Commerce.

\section{Dr. Amir W Al-Khafaji, Bradley University}




\title{
Internationalization and Civil Engineering Program Innovation
}

\begin{abstract}
In the early 1990's, the Department of Civil Engineering and Construction (CEC) at Bradley University developed strategic objectives to introduce internationalization to our students and curriculum. Initially, four objectives for the CEC Global Explorer Program were outlined: 1) to send students abroad for study either for a short mini-semester or full semester; 2) persuade international students to come to Bradley; 3) embark on a faculty exchange; and 4) to foster international research exchange between the CEC department and institutions abroad. In 1996, the Bradley University's International Program was limited to the summer months. The involvement of engineering students and faculty was extremely limited for at least two reasons. First, many course offerings were for language studies or general education. A more important reason was that most engineering students preferred or were obligated to work during the summer months. Summer employment was important to gain experience and for financial reasons as Bradley is a private institution. Yet faculty and students could benefit greatly from international exposure. More importantly, the internationalization program inspired the faculty to modify the curriculum to better reflect the changing realities of our engineering profession. The new CEC curriculum permit students to seek emphasis in international program, sustainability, or infrastructure.
\end{abstract}

The CEC had the vision and foresight to realize the paramount importance of international education to the future of the civil engineering and construction professions. The mindset was that future employers would be seeking engineers with some international experience and exposure to the various cultures. Furthermore, ABET promoted internalization by one of its outcomes: "broad education necessary to understand the impact of engineering solutions in a global, economic, environmental, and societal context." Therefore, the Department of Civil Engineering and Construction conceived of an idea to hold an international study abroad during its January interim, a mini-semester of 2-3 weeks long (depending on destination) during which students and faculty pursue one course full time. The study abroad program is one of the most successful in the country as described by one recent accrediting team visiting team.

Despite some detractors who thought engineering courses could not be taught abroad because of the brevity of the January interim and the complexity of the program, the department persevered in planning by sending faculty abroad to England and Denmark to investigate possibilities of bringing a group of CEC students. Since 1996, the CEC Global Explorer Program has expanded to Sweden, Denmark, Norway, England, France, Jordan, Egypt, and Malta. Also, CEC leads Bradley University in the number of students and faculty participating in study abroad. In fact, the Bradley Summer program has shifted to a more robust January interim program. After describing the early developments of the CEC Global Explorer Program, this paper will also explore how the emphases on internationalization and sustainable development were integrated into the CEC curriculum. 


\section{Introduction}

Rapidly advancing technology in areas such as communications, computers, building infrastructure continue to bring the globe into a tightly woven "global market place". As the USA moves toward a service economy, multi-national companies provide services all over the globe. In addition to business connections, many difficult and common challenges face the world in terms of sustainable infrastructure. Natural disasters such as Katrina and Japan's tsunami have had ripple effects throughout the world, and the repair to infrastructure will take years before normalcy returns. Water scarcity and clean sources of drinking water are problems faced by many countries ${ }^{1}$. In 15 years, 1.8 billion people will live in regions of severe water scarcity. As the world's population continues to grow, city infrastructure will be strained as close to five billion people will be living in cities by 2030. Already, half of the world's population lives in cities, most of which have inadequate infrastructure and resources to address wastewater management in an efficient and sustainable way. Twenty-one of the world's 33 megacities are on the coast where fragile ecosystems are at risk. Figure 1 shows coastline around the globe where hypoxic conditions exist; i.e. low dissolved oxygen resulting from untreated wastewaters and nutrient rich runoff ${ }^{2}$. Currently an estimated $245000 \mathrm{~km}^{2}$ of marine ecosystems are affected with impacts on fisheries, livelihoods and the food chain ${ }^{3}$.

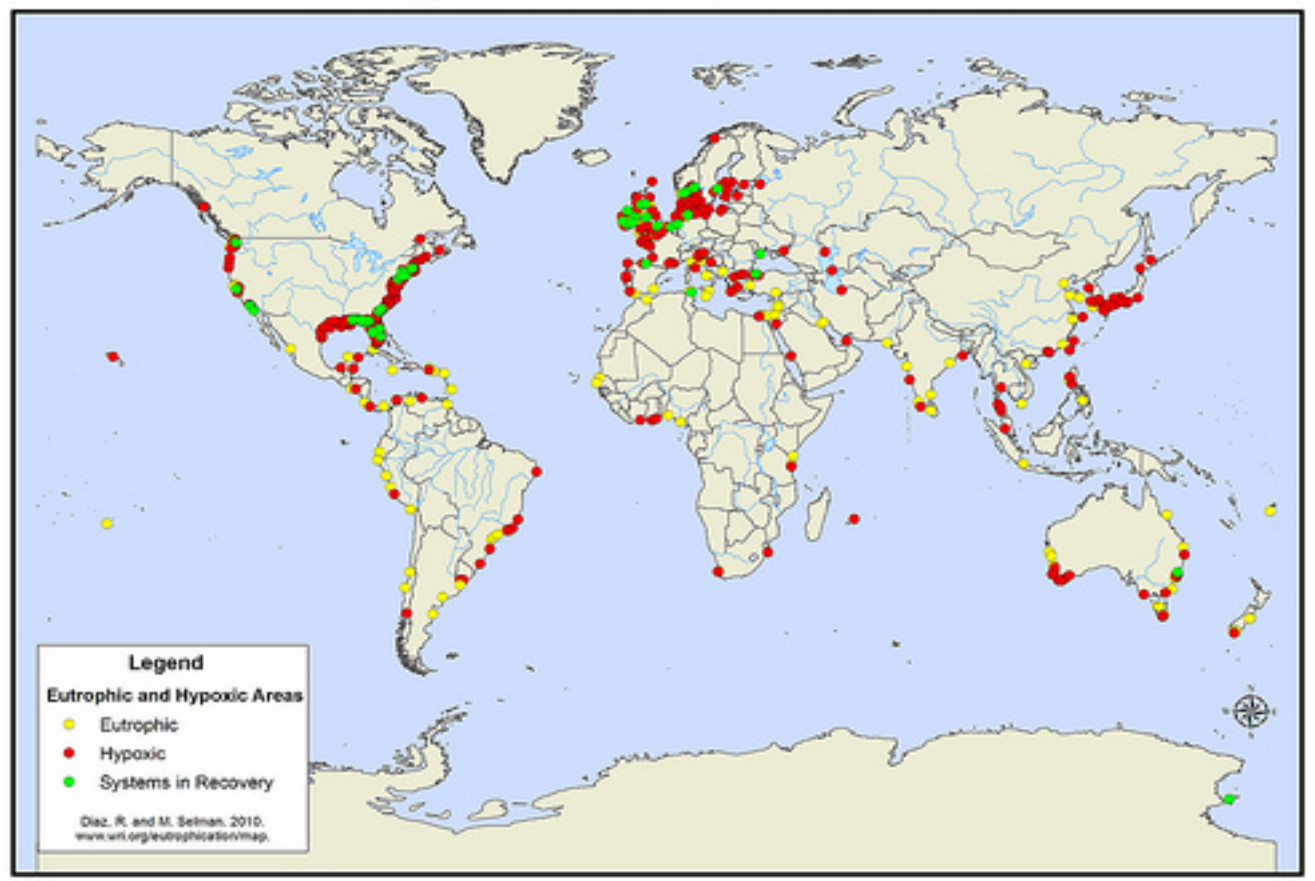

Figure 1. World Hypoxic and Eutrophic Coastal Areas ${ }^{2}$

Although the nature of the infrastructural challenges may be common around the globe, the local response to various challenges may differ because of financial, educational, political and other factors that influence a local solution. Therefore, respect, sensitivity and an understanding of various cultures must be incorporated into the education of tomorrow's civil engineers and constructors who can help design, analyze, and build sustainable infrastructure. Respect for technology transfer which can flow either way between developed and developing countries ${ }^{4}$. 


\section{Internationalization and Engineering Accreditation}

Another imperative for incorporating internationalization into the study of civil engineering and construction comes from the Accreditation Board for Engineering and Technology, (ABET). Eleven outcomes also simply labeled as "a-k" describe the characteristics that students should have upon graduation. Three outcomes are pertinent to internationalization; outcome $\mathrm{h}$ stipulates that graduates possess a "broad education necessary to understand the impact of engineering solutions in a global, economic, environmental, and social context" outcome tie sustainability and internationalization close together. The three legs of sustainability are economic, environmental, and social aspects - all of which relate to the infrastructure that society relies on, built by civil engineers and constructors design around the world. There are common themes but also distinguishing one between cultures regarding the design, building, and use of that infrastructure. As the USA moves toward a service economy, and engineering and construction firms reach out around the globe, it is essential to prepare civil engineers/constructors to meet the challenge.

Outcome $\mathrm{j}$ of ABET requires that students have a "knowledge of contemporary professional practice issues in management, business, public policy, and leadership in a multicultural and social context", Internationalization is also deeply embedded in this outcome. Civil engineering consulting and construction are businesses that manage the project from its very conception through the building phase. Civil infrastructure is often dependent on government policy and funding in any country around the globe. Hence, civil engineers and constructors need to be visible leaders in public policy ${ }^{6}$.

Outcome c mentions a student's study includes "sustainability" which is also included in the American Society of Civil Engineers (ASCE) code of ethics ${ }^{5,7}$. ASCE is a member of several forums at the national and international levels to provide a continuing education and communication that includes sharing experiences with sustainable technologies, promoting public understanding of sustainable development, and encouraging the integration of sustainable practices into civil engineering ${ }^{7}$.

In the Department of Civil Engineering and Construction (CEC) at Bradley University, a multifaceted study abroad program and internationalization emphasis has been a continuously expanding program since the early 1990's. In this paper, the obstacles to establish a study abroad program at Bradley University and how they were overcome them. This paper also describes how internationalization has become one of the areas of emphasis for the CEC curriculum. Companion papers describe other facets of the CEC internationalization program and how its impacts students $6,8,9$.

\section{Early Development of CEC Internationalization}

In the early 1990's, Bradley University's International Program was limited to the summer months mostly for students pursuing language studies or general education courses. Bradley had established agreements with universities in Czech Republic, Denmark, Germany, Great Britain, Hungary, Japan, Mexico, Russia, Sweden, Italy, and Malta. The involvement of engineering students and faculty was extremely limited for at least two reasons. First, many course offerings 
were for language studies or general education; there were no course transfers for engineering courses. Another equally important reason was that most engineering students preferred or were obligated to work during the summer months. Summer employment was important to gain experience and for financial reasons as Bradley is a private institution.

In the early 1990's, the CEC had the vision and foresight to realize the paramount importance of international education to the future of the civil engineering and construction professions. The mindset was that future employers would be seeking engineers with some international experience and exposure to the various cultures. In order to overcome the difficulties facing engineering students' involvement in international study, CEC proposed that course be taught overseas during the January interim which is a $2.5-3$ week interval in early January before the beginning of the spring semester. During this interim, a student is permitted to study full-time one course in an accelerated manner thereby gaining a full semester's credit for that course. The reaction from other engineering departments was that it could not be done, especially because of the demand engineering courses. However, when departments outside the College of Engineering heard about CEC's January plan, both the English and History departments decided to tag along on the trip.

In 1995, two CEC faculty went abroad; one to Denmark and one to England. Their purpose was to plan for a study abroad, inspect potential venues for the students, and to arrange for course transfer credits for engineering courses. After a survey of CEC students concerning the country and course they would prefer, an environmental engineering course was selected to be taught in London England during the January interim of 1996. CEC appealed to industrial partners for financial contributions to help support students taking this first study abroad. CEC has been blessed with many industrial partners who have supported the department, but only one at the time decided that international study abroad was a worthwhile cause.

A group of ten students studied in London during the January interim. In addition to enjoying different cultural experiences such as the theater, students also experienced relevant to civil engineering and construction. Highlights included a trip to Cambridge and a tour of their facilities with talks provided by faculty and $\mathrm{PhD}$ students there. Another highlight was a trip to Paris using the Chunnel to see the sights in Paris including the Eiffel Tower. Because CEC has the foresight to establish course equivalency transfers, CEC was also able to send two students abroad for semesters of study. One student went to Denmark during the spring, 1996, to study photogrammetry and Geographical Information Systems. This student attributed his study abroad to subsequently getting a scholarship from Boeing Co. Another student went to England for study for one academic year.

After this first year of international study, CEC expanded the number of excursions in England and France to include numerous items of interest for engineering and construction. CEC has also expanded to many more courses being offered in various countries such as Denmark (with side trips to Sweden and Norway) and to Egypt (with excursions all over Egypt and to Jordan). These trips are highlighted in Figure 2. In addition to realizing the four points of its internationalization strategic plan, CEC has interacted with business partners by escorting two groups of CEO's and introducing them to government leaders abroad in order to facilitate bids for projects abroad. All of these expanded initiatives are discussed in more detail in companion papers ${ }^{6,8,9}$. 


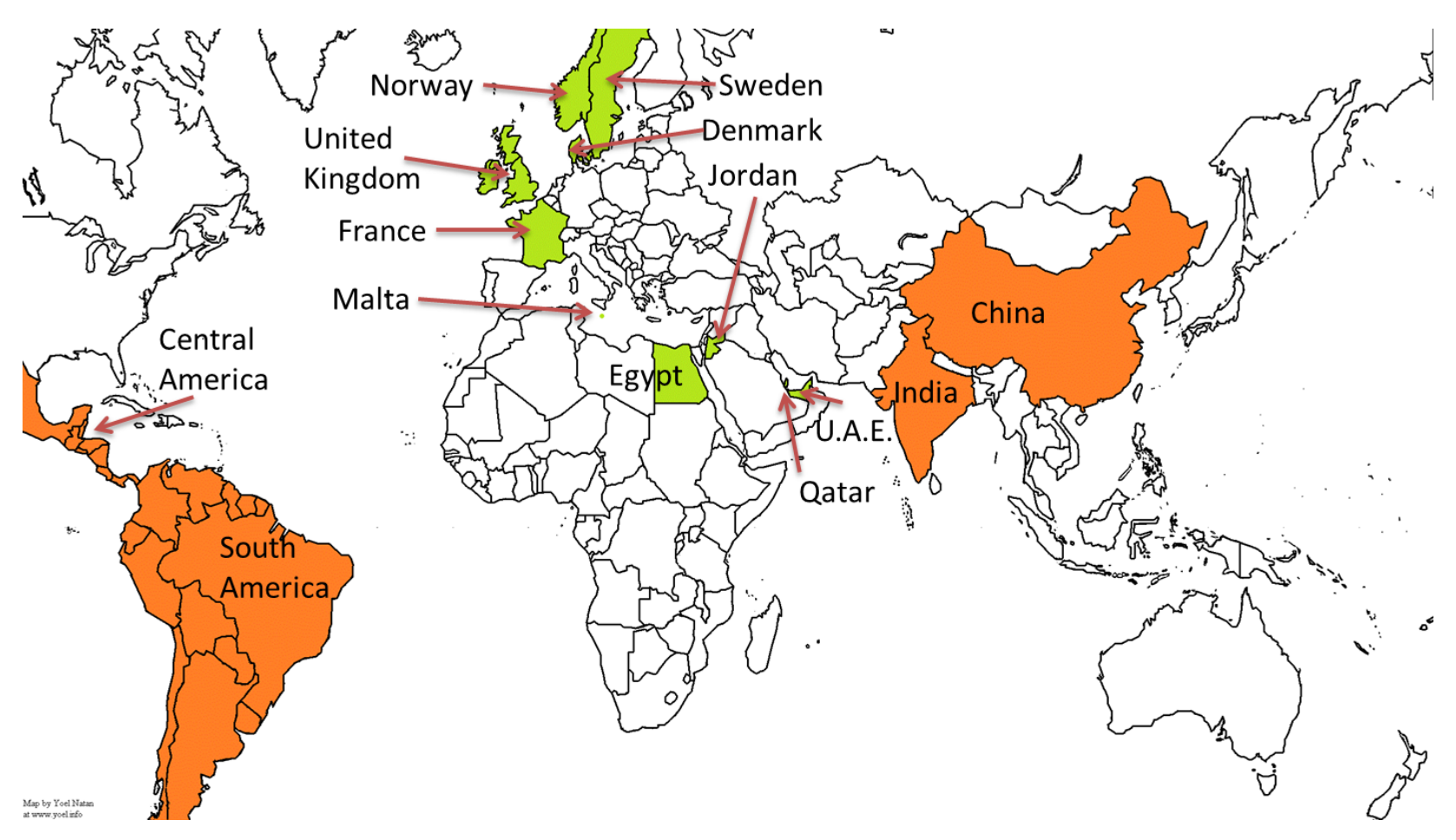

Figure 2. Destinations for CEC Internationalization Program

(Green denotes countries visited and orange denotes future destinations)

The remainder of this paper is devoted to how the international program has become an area of emphasis for our program of study for civil engineers and constructors. In 2008, the CEC department modified its program to center on three areas of emphases: internationalization, sustainability, and infrastructure. A brief description of how internationalization is incorporated in several of these courses.

\section{Internalization as an Area of Emphasis in CEC}

The emphasis of CE 393, Sustainability and Public Policy is to introduce the students to how sustainability impacts the civil engineering profession. A sustainable design team and design process is different from conventional designs. International case studies are presented of sustainable designs for different cultures with different types of local problems ${ }^{10}$. Students are exposed to an international state of water, energy and environmental issues. In CE 555, Sustainability and Environmental Regulations, international issues such as climate change, ozone depletion, hazardous waste trading, and green initiatives in China are addressed ${ }^{11}$. Hopefully, future decades will see international firms and governments work with civil engineers and constructors to resolve and alleviate some of the human infrastructural burdens as discussed in the introduction. However, it is not merely a technical problem, but also financial, technological, political, educational, and even cultural differences must be taken into account. Hence, there is a need for students to be informed of public policy, leaderships, and internationalization (ABET outcome j). 
CE 493 and CE 498 provides a one year sequence of senior design. Three tracks of study, structural, environmental, and transportation are available for students to select the section of study they prefer. An industrial partner is the primary instructor for each course in coordination with CEC faculty. Each partner brings a real-world example for students to work out the design with all practical and real details. As part of this course, one industrial partner with international consulting experience provides a lecture on how and in what ways internationalization is important for students.

One way to evaluate the success of CEC's internationalization program is that CEC has led the University in terms of number of students participating in study abroad. Another way to assess the impact of CEC internationalization program is by student surveys at all levels and by a senior "exit interview". During this latter interview, seniors and selected CEC faculty discuss ways to improve the CEC academic program in general. CEC's internalization program has been one of the highest ranked activities by students. Currently CEC is considering planning trips to other countries for its next study abroad during January, 2015. During spring 2014, CEC is surveying students for courses of interest and preferred countries for destination. Based on a previous survey, countries being proposed are: UAE, Jordan, India, and China. These planning trips are essential because during these trips, all arrangements are made for housing and for excursions that happen just about every day. Planning trips also are instrumental in making the student trips cost effective. CEC has always had its sights on expanding the internationalization program in terms of different countries to visit.

\section{Summary and Conclusion}

Bradley University internationalization program was mostly about language studies and general education courses. Since the early 1990's CEC has continuously expanded its internalization emphasis for its students. This internationalization program is multi-faceted in its implementation and in its impacts on many people. In addition to a general education of cultural awareness and respect, internationalization is important to CEC's industrial partners and to future civil engineers/constructors who are being educated to take leadership roles to tackle global challenges and projects.

\section{Bibliography}

1. National Geographic, "Water Our Thirsty World”, April, 2010.

2. WRI, (World Resources Institute), 10 G Street NE Suite 800, Washington, DC 20002, USA / http://www.wri.org/our-work/project/eutrophication-and-hypoxia/interactive-map-eutrophication-hypoxia

3. UNEP, Sick Water? The Role of Wastewater Management in a Sustainable World, http://www.unep.org/pdf/SickWater screen.pdf (last accessed March 7, 2014)

4. Mihelcic, James R., Zimmerman, Julie B., and Ramaswami, Anu, 2007. "Integrating Developed and Developing World Knowledge into Global Discussions and Strategies for sustainability. 1. Science and Technology," Environmental Science \& Technology, 41(10):3415-3421.

5. Al-Khafaji, Amir W. and Elhouar, Souhail, "Preparing Engineers for Global Challenges,"

6. Grant, Albert A., 2007. "American Society of Civil Engineers Signs Sustainability Protocol”, Environmental Progress 26(2): 127-128. 2007 
7. Al-Khafaji, Amir W. and Maillacheruvu, Krishnanand Y., "Impact of International Collaboration on the Learning Environment,"

8. Al-Khafaji, Amir W. and Schattler, Kerrie, "An Engineering Faculty Perspective on Shared Global Experiences,"

9. Sarte, S. Bry, 2010. Sustainable Infrastructure, John Wiley \& Sons

10. Vig, Norman J. and Kraft, Michael e., 2013. Environmental Policy: New Directions for the Twenty-First Century, CQ Press, Washington DC 